Research, Society and Development, v. 7, n. 8, p. 01-10, e978337, 2018

ISSN 2525-3409 (CC BY 4.0)

\title{
A Importância do Raciocínio Lógico Para a Metodologia da Pesquisa: Raciocínio, Planejamento e Execução
}

\section{The Importance of Logical Reasoning for Research Methodology: Reasoning, Planning and Execution}

\section{Jander Temístocles de Oliveira}

Faculdade de Ciências Médicas da Santa Casa de São Paulo, Brasil

E-mail: jander_temistocles@yahoo.com.br

Alexsander Zanotti

Fundação Instituto de Administração, Brasil

E-mail: a_zanotti@uol.com.br

Recebido: 30/03/2018 - Aceito: 20/04/2018

\begin{abstract}
Resumo
O estudo tem por objetivo reafirmar a importância de saber pensar e seus métodos, a fim de traçar um paralelo entre as formas de raciocínio ao longo do desenvolvimento da mente humana e os modelos metodológicos para planejar e executar uma pesquisa científica. Analisamos artigos e publicações que trouxeram em seu escopo tanto as fases do raciocínio e métodos, como diferenças etárias de pensamento crítico e analítico e sua progressão. Como podemos observar, os estudos ainda necessitam avançar na perspectiva do raciocínio lógico em adultos, já que há bastante material contemplando estudos em crianças e adolescentes. Contudo, temos bases suficientes para declarar que tal raciocínio sofisticado que a mente adulta produz, se apresenta complexo e completo o suficiente para ser classificado maduro e necessário ao método científico.
\end{abstract}

Palavras-chave: Raciocínio; Método; Metodologia da pesquisa; Pensamento crítico.

\begin{abstract}
Acknowledging the importance of knowing how to think and its methods to draw a parallel between the forms of reasoning accompanying cognitive changes in the human mind and the methodological models to plan and execute scientific research was the objective of this study. We analyzed articles and publications that brought in their scope both the phases of reasoning and methods, as well as age differences in cognition, critical and analytical thinking development. As we can see, studies still need to advance from the perspective of logical reasoning in adults, since there are enough material contemplating studies in children and adolescents. However, we have sufficient grounds to declare
\end{abstract}


that such sophisticated reasoning that the adult mind produces is complex and complete enough to be matured and necessary to scientific research.

Keywords: Reasoning; Method; Research; Critical thinking.

\section{Introdução}

Antes de enveredarmos pela conceituação e entendimento do que vem a ser raciocínio lógico e metodológico, convém verificarmos, mesmo que superficialmente, o que vem a ser o pensamento crítico, elemento basilar do raciocínio crítico e operações lógicas do pensamento que se corporificarão em métodos, que por sua vez, nortearão uma investigação ou pesquisa.

Para Carbogim et al. (2016), a Filosofia tenta definir um pensador crítico hipotético, baseando-se em suas qualidades e características, enquanto a Psicologia busca descrever o pensador crítico baseado em suas habilidades ou ações.

Adotaremos, inicialmente, a visão filosófica dada a natureza e propósito deste estudo, onde podemos extrair dois princípios norteadores do pensamento crítico: qualidade e características.

A qualidade do pensamento crítico dependerá do modo de refletir sobre um dado assunto ou problema privilegiando a integridade intelectual cujas características são a compreensão competente de concepções e preceitos e a exatidão para reconhecer e evidenciar as particularidades dos argumentos, em busca de objetividade.

As operações lógicas do pensamento não são uteis apenas para o uso matemático, mas também para o bom entendimento da própria linguagem, dado que ela é responsável por comunicar as ideias e pensamentos de modo lógico e coerente. Mais adiante, apresentaremos essas operações lógicas e seus modelos, bastando para este momento evidenciar aquilo que Schipper e Vestena constataram em seu estudo que a não mobilidade do pensamento operatório - raciocínio por transdução e por experiência mental e dificuldade em compreender a lógica das relações - produzirá a falha nos agrupamentos gerando a incapacidade de multiplicação lógica. O agrupamento é a condição sine qua non para o raciocínio lógico e, isolando esse mecanismo, Inhelder conseguiu compreender os agrupamentos presentes na ação do raciocínio do aluno com Deficiência Intelectual, constatando, de acordo com Ramozzi-Chiarottino (2002), a ausência de agrupamentos nas ações e nos discursos. (Schipper e Vestena, 2016, p.81)

Como podemos observar, a incapacidade de multiplicação lógica dentre outras, caracteriza a Deficiência Intelectual e, consequentemente, na ausência de um pensamento 
analítico, a criança concentra diferentes objetos em um único vocábulo, fazendo com que seus conceitos sejam dominados pelo sincretismo, que, em seu apego a detalhes, liga tudo a tudo sem sintetizar ou relacionar. Tal traço de pensamento ou raciocínio imaturo produzirá um adulto incapaz ou semi-capaz de raciocínio crítico e lógico.

Depreende-se então, que todo aquele que não seja portador de DI seja capaz de realizar multiplicações lógicas dentro de um pensamento analítico, ou seja, realizar raciocínio lógico tão necessário para a pesquisa científica e desenvolvimento de projetos de pesquisa.

Assim, o estudo tem por objetivo reafirmar a importância de saber pensar e seus métodos, a fim de apresentar um paralelo entre as formas de raciocínio ao longo do desenvolvimento da mente humana e os modelos metodológicos para planejar e executar uma pesquisa científica.

\section{Metodologia}

Adotamos para este estudo uma pesquisa de publicações científicas onde foram buscados artigos na Plataforma Scielo com as palavras raciocínio; pesquisa. Foram encontrados 132 artigos com data de publicação até fevereiro de 2018, sendo que destes, apenas 6 atenderam à necessidade desta pesquisa exploratória no que diz respeito aos critérios de inclusão para esta revisão, ou seja, as formas de raciocínio em idade infantil e adulta, madura e imatura. No entanto, a fim de atender à necessidade metodológica de validação da análise qualitativa deste estudo, recorremos a outras publicações que não estão na Plataforma Scielo, mas em ferramenta de busca e/ou livros que trazem informações que não podem ser desprezadas por esta revisão.

\section{Discussão}

Conforme apresentamos na introdução, a Filosofia busca definir o pensador crítico baseando-se em suas qualidades e características (Carbogim et al. 2016) de modo que no âmbito da educação, enfoca-se as habilidades de ensino e aprendizagem.

Carbogim também caracteriza o pensamento crítico como um pensamento de alto nível que envolve conhecimento, experiência, atitudes mentais e habilidades intelectuais.

Em seu estudo Schipper e Vestena (2016) declaram que o raciocínio por experiência mental implica despreocupação com as contradições do pensamento, já que as hipóteses não demandam comparações e comprovações, que podemos inferir de sua afirmação que o 
pensamento crítico e analítico implica uma preocupação com as contradições do pensamento (tese/antítese) que demandam comparações e comprovações, caracterizando assim, um alto nível de processamento mental e cognitivo.

De acordo com as autoras, o raciocínio por experiência mental caracteriza o sujeito ou aluno com DI (Deficiência Intelectual) que não raciocina logicamente mas elabora seus juízos de controles de hipóteses pela experiência mental que se caracteriza por uma reprodução do pensamento e dos acontecimentos do modo como eles se dão de fato na natureza.

Alguns anos antes da constatação de Schipper e Vestena, outra pesquisadora M. G. B. Borges Dias (2000) investigou as habilidades do raciocínio silogístico usadas para alcançar conclusões e detectar incoerência em textos por parte de crianças em idade escolar, constatando que vários fatores são responsáveis pelo baixo desempenho encontrado no estudo de Markman (1979) se devia ao fato de que um dos fatores seria o fato dos três componentes do argumento lógico (duas premissas e a conclusão) estarem misturadas em nove sentenças, o que deve ter sobrecarregado a memória a curto prazo. Depreendemos desta observação que a memória assume importante papel na produção do pensamento crítico ou analítico, elemento esse que retomaremos em seguida.

Conforme Borges Dias prossegue em seu raciocínio, ao se comparar os dados obtidos nos estudos sobre a capacidade de fazer inferências lógicas per se com os de estudos sobre a consciência pragmática, percebe-se que crianças bem jovens são capazes de fazer inferências silogísticas quando as premissas lhes são apresentadas isoladamente, fora de um texto mais amplo. No entanto, são necessários alguns anos mais para que este tipo de raciocínio lógico possa ser utilizado para derivar conclusões, ou detectar incoerências referentes a premissas contidas em uma história ou texto.

Retomando ao aspecto da memória envolvido no processo e produção do pensamento crítico, temos a publicação de Almeida e Primi (2004) que declararam que os modelos então mais recentes sobre a estrutura da inteligência se organiza hierarquicamente em dez áreas amplas de raciocínio, dentre elas, memória de curto prazo referindo-se à habilidade associada à manutenção de informações na consciência por um curto espaço de tempo e o armazenamento e recuperação da memória de longo prazo definido como a extensão e fluência que itens de informação ou conceitos são recuperados e que sustentam a capacidade de raciocinar utilizando conceitos previamente aprendidos.

Andriola (1997) realizou uma pesquisa sobre a avaliação do raciocínio verbal em estudantes do $2^{\circ}$ grau para avaliar a capacidade cognitiva denominada de raciocínio verbal em estudantes do $2^{\circ}$ grau constatando que os alunos homens (média 8,59) apresentaram 
desempenho médio um pouco superior às mulheres (média 8,57) ao considerar os gêneros. Considerando a idade, os alunos mais velhos obtiveram desempenho médio superior às outras duas faixas etárias, também com variabilidade menor. Quanto a avaliação do raciocínio, deve ser mencionado que se trata de uma atividade relevante para a compreensão de problemas frequentes na área da psicologia escolar, sobretudo aqueles associados às dificuldades de aprendizagem e baixo rendimento escolar dos estudantes.

Em um estudo voltado para o público adulto, Silva e Frezza (2011) iniciam sua publicação declarando que estudo do pensamento do adulto apresenta algumas particularidades metodológicas que dificultam a investigação, pois aquele apresenta estruturas e processos de pensamento singulares, em contraste com o infantil em termos de desenvolvimento psicogenético.

Declaram ainda que, além das estruturas gerais de pensamento, pode-se investigar os procedimentos de resolução de problemas, isto é, os aspectos funcionais do raciocínio em adultos - as especificidades dos conteúdos.

No que se refere à significação, diante de um conteúdo novo, mesmo um sujeito adulto tem a necessidade de se (re) organizar frente às novidades. No entanto, diferente da criança, o adulto consegue (re) elaborar suas ideias muito mais rapidamente. Não é diferente no modo de operação do raciocínio lógico matemático, onde o primeiro estágio dará ao bebê a possibilidade de identificar que as coisas não desaparecem quando retiradas do seu campo de visão. O segundo deixará a criança organizar seus próprios movimentos e dos objetos no espaço. Em seguida, com o advento da função semiótica, a estrutura lógico-matemática ascende a um novo patamar. Aquilo que, inicialmente, no período sensório-motor caracterizava-se por uma organização prática, desdobra-se agora numa construção simbólica para então, no estádio operatório-concreto, as ações interiorizadas do período pré-operatório passam a ser organizadas sob a forma de operações lógico matemáticas que indicam maiores mudanças estruturais. Assim, baseados em Piaget e Inhelder, sua hipótese é de que, quando o sujeito se ocupa de um problema, as operações e a estrutura proporcionam uma dimensão lógico-matemática para abordar a situação.

Silva e Frezza apresentaram em seu artigo as peculiaridades metodológicas na pesquisa da inteligência destes sujeitos (adultos). A dificuldade oriunda das inúmeras possibilidades de estruturação lógico-matemática favorece a investigação através de um viés diferenciado, isto é, do sujeito psicológico.

Por último e não menos importante, o estudo realizado por Friend e Zubek (2016) constatou que a habilidade de pensar criticamente tem um aumento progressivo do final da 
infância até meados dos vinte anos, estende-se aos 35 anos e depois declina progressivamente até os setenta anos.

Dada a carência de outras publicações em revistas científicas específicas, apresentamos a seguir trechos de algumas obras ou citações que trazem em seu escopo o objeto ora estudado, o pensamento crítico.

$\mathrm{Na}$ perspectiva da comunicação comparada ou semiologia, para a geração do conhecimento o indivíduo parte em princípio da observação do universo natural, segundo Brosso e Valente (1999) "um signo ou um representamen é uma espécie de terceiro, isto é, pode ser entendido como uma relação triádica. Fundamentalmente é um primeiro, que põe um segundo, seu objeto ou referente, em relação cognitiva com um terceiro, seu interpretante, de forma que este assuma a mesma relação triádica (com o objeto) que ele, signo, mantem em relação ao mesmo objeto", ou seja o primeiro estágio é a observação conceitual de um signo que não se expressa por si só, sendo conceito puro e bruto em imagem e ideia, um ícone, parte de uma tricotomia composta por ícone, índice e símbolo. O embasamento teórico - segundo estágio na construção de um conceito precisa buscar suas bases em métricas estabelecidas nas faculdades do conhecimento humano de desejo, lastreada por fundamentações técnicas, cientificas inerentes aos objetivos da busca, segmentando informações e criando agrupamentos conceituais sobre o objeto de estudo. Experimentação - terceiro estágio para comprovação do conceito se dá a partir da planificação numérica do objetivo almejado. $\mathrm{O}$ raciocínio lógico começa na fixação do olhar norteado pela sua fundamentação empírica (observação natural) ou experimental (observação natural a partir de regras estabelecidas). Segundo Aristóteles, a lógica não é ciência e sim um instrumento (órganon) para o correto pensar.

Conforme aponta Linda Elder (1996), através do pensamento crítico, como entendido, adquirimos um meio de avaliar e melhorar nossa capacidade de julgar bem (correto pensar). Isso nos permite entrar em praticamente qualquer situação e descobrir a lógica do que está acontecendo nessa situação. Proporciona uma maneira de aprendermos com novas experiências através do processo de autoavaliação contínua. O pensamento crítico, então, nos permite formar crenças e julgamentos sólidos e, ao fazê-lo, nos fornece uma base para uma vida emocional "racional e razoável".

"Não restam dúvidas de que os jogos são uma grande ponte para o divertimento e o aprendizado! Eles compõem um caminho útil para ampliar a memória e o raciocínio lógico em adultos e crianças, que podem ser levados para a vida acadêmica e profissional." Tal concepção (publicada em: 15-09-2017 pela PROEX - Pró-Reitoria de Extensão da UFMG) 
vem ao encontro de nossa perspectiva apontando caminhos de estudos e aplicações, corroborando a proposição de Elder, supracitada, na formação de crenças e julgamentos válidos.

Leifer e Fleck, (2013) sugerem que habilidades intelectuais e criativas melhoram com a educação e a experiência, em conformidade com Piaget que acreditava que o desenvolvimento da operação formal como um modo de pensar se inicia na adolescência e se estende pelo início da vida adulta. Assim, o nível do pensamento abstrato e do raciocínio lógico é aprimorado pelo uso da tecnologia que está disponível no dia-a-dia, tal que o processo cognitivo de jovens adultos envolve perceber que o conhecimento consiste na integração de muitos pontos de vista e que este processo de integração de vários pontos de vista para desenvolver o conhecimento e compreensão é muitas vezes referido como pensamento operacional pós-formal, e que os indivíduos hábeis neste pensamento ou que o desenvolveram bem, são melhores na resolução de problemas, de um modo geral.

Levine (2017) ao enfocar o público adulto na revista Spy -, o Poder do enigma: Os 8 melhores livros de lógica e quebra-cabeças para os treinos mentais, declara que jogos mentais, incluindo quebra-cabeças, desafios de trivia, enigmas e resolução de problemas são todos projetados para não apenas desafiar suas habilidades, mas também manter seu cérebro jovem. Assim como o exercício ajuda a manter seu corpo em forma e funcionando, os jogos de quebra-cabeça ajudarão a manter seu cérebro ativo e a dar uma vantagem cognitiva àqueles que os jogam regularmente, justificando, por assim dizer, a adoção de jogos pela PROEX, previamente mencionada aqui.

\section{Modelos metodológicos}

Um método científico se caracteriza pela forma de proceder para construir um objeto de pesquisa. Assim, o objeto construído pelo método aplicado terá suas características. Já os modelos metodológicos se estruturam assim conforme Koyré (1982):

1. A escolástica;

2. O modelo empirista;

3. O modelo sistêmico;

4. Métodos adequados.

Organizamos, a título de ilustração, a seguinte figura para sintetizar os tipos de pesquisa, diferenciando-os dos modelos acima: 


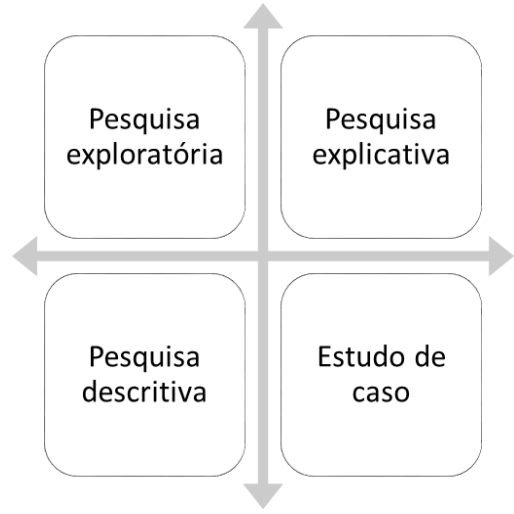

Fig. 1 - tipos de pesquisa - elaborado por nós

\section{Conclusão}

Como podemos observar, os estudos ainda necessitam avançar na perspectiva do raciocínio lógico em adultos. Contudo, temos bases suficientes para declarar que tal raciocínio sofisticado que a mente adulta produz, se apresenta da seguinte maneira:

Levantamento dos elementos constituintes ou Premissas | Planejamento e estratégias e/ou Execução | Observação dos resultados ou Conclusão/Solução.

Tal configuração é necessária para o sucesso na elaboração de uma metodologia de pesquisa utilizando-se do raciocínio lógico em suas modalidades, ou seja, dedução, indução e abdução.

O presente estudo se vê ainda limitado pela escassez de publicações direcionadas ou aplicadas ao raciocínio lógico em adultos e sua importância para a metodologia e pesquisa científica bem como dos modelos metodológicos padronizados que é preocupação dos pesquisadores de várias áreas para que haja a definição de procedimentos metodológicos padronizados.

A importância de saber pensar e seus métodos é a base do raciocínio que, por sua vez, é elemento basilar da metodologia da pesquisa científica. Assim, futuras publicações deste escopo contribuirão para o aperfeiçoamento de modelos já existentes e, provavelmente, proverão bases de estudo teórico para a aplicação da Inteligência Artificial (A.I) atuando como mediadora nos modelos metodológicos padronizados. 


\section{Referências}

ALMEIDA, Leandro S.; PRIMI, Ricardo. Perfis De Capacidades Cognitivas Na Bateria De Provas De Raciocínio (BPR-5): Capacidades cognitivas e BPR-5. Psicologia Escolar e Educacional, 2004 Volume 8 Número 2 135-144.

BROSSO, Rubens; VALENTE, Nelson. Elementos de Semiótica: Comunicação verbal e alfabeto visual. São Paulo: Panorama, 1999.

CARBOGIM FC, OLIVEIRA LB, PÜSCHEL VAA. Critical thinking: concept analysis from the perspective of Rodger's evolutionary method of concept analysis. Rev. Latino-Am. Enfermagem. 2016;24: e2785. [Acesso em 20.02.2018]; disponível em: www.eerp.usp.br/rlae. DOI: http://dx.doi.org/10.1590/1518-8345.1191.2785.

DIAS, Maria da Graça Bompastor Borges. Raciocínio Lógico, Experiência Escolar e Leitura com Compreensão. Psicologia: Teoria e Pesquisa Jan-Abr 2000, Vol. 16 n. 1, pp. 055-062.

ELDER, Linda. Critical Thinking Across the Disciplines. CriticalThinking.org | Winter, 1996. Vol. XVI, No. 2.

FRIEND, Celia M; ZUBEK, John. The Effects of Age on Critical Thinking Ability. Penn State University (Paterno Lib) on September 18, 2016 http://geronj.oxfordjournals.org/

KOYRÉ, A., (1973). Estudos de história do pensamento científico. Tradução Márcio Ramalho. Brasília: Editora Universidade de Brasília, 1982 (Campo teórico).

LEIFER, Gloria. FLECK, Eve. Growth and Development Across the Lifespan - E-Book: A Health Promotion Focus. - 2nd ed. http//:evolve.elsevier.com

LEVINE, Lisa. Puzzle Power: The 8 Best Logic, Puzzle and Brain Teaser Books for Mental Workouts. http://spy.com/2017/entertainment/books-music-movies/brain-puzzle-books-logicteasers-riddles-78195/ acesso em: 17/04/2018. 
SCHIPPER, Carla Maria de; VESTENA, Carla Luciane Blum. Características do raciocínio do aluno deficiente intelectual à luz da Epistemologia Genética. Psicologia Escolar e Educacional, SP. Volume 20, Número 1, Janeiro/Abril de 2016: 79-88. http://dx.doi.org/10.1590/2175-3539/2015/0201931

SILVA, João Alberto da; FREZZA, Júnior Saccon. Aspectos metodológicos e constitutivos do pensamento do adulto. Educar em Revista, Curitiba, Brasil, n. 39, p. 191-205, jan./abr. 2011. Editora UFPR 